\title{
Exploraciones Botánicas en el Norte del Estado de Duebla
}

\author{
Por el doctor LADISLAO PARAY
}

A mediados del mes de septiembre de este año (1945) en compañía de varios miembros de la Sociedad Botánica de México realicé una excursión en la sierra situada en los límites del Estado de Puebla e Hidalgo. Por ferrocarril llegamos a la pequeña estación de Honey, desde donde emprendimos la marcha hacia los pintorescos poblados de Pahuatlán, Tenango de Doria, San Bartolo y Tutotepec. El objeto principal del viaje era visitar los extensos bosques de hayas (Fagus) en la región de Tutotepec.

Salimos una mañana lluviosa de Honey hacia la tierra caliente. Caminamos entre bosques de frondosos encinos de unas hojas muy oscuras, casi azulosas. Entremezclado con los encinos (Quercus) había gran variedad de Ericáceas como Arctosphylos, Arbutus, Vaccinium, Pernettya, Leucothoe, Gaultheria acuminata, etc. Abundan los arbustos de Ternstroemia con sus frutos maduros muy coloridos. Debajo de los árboles crece una interesante Hypericácea: el Ascyrum hypericoides. La vegetación nos recuerda mucho la zona de Huauchinango y Necaxa. Conforme vamos bajando encontramos más especies semitropicales. Aparece la Bernardia interrupta, Clibadium, Ocimun Selloby, Lencocarpum, Cnidoscolus, Pillaea, Oreopanax, Gilibertia, etc. Las peñás están adornadas por la bellísima trepadora: Maurandia erubescens.

Uno de los hallazgos más notables para mí es la hermosa Escrofulariácea Gerardia tenuifolia. En mis correrías de más de veinte años por las sierras de México nunca había encontrado esta planta, por lo tanto al encontrarla me era desconocida. Supongo que debe ser bastante rara, ya que el insigne botánico doctor Miranda tampoco la había encontrado hasta la fecha. Sin embargo, nuestro compañero de viajes, señor E. Hernández, la identificó como Gerardia. Esta planta, según Bailey,

Paray L. 1946. Exploraciones botánicas en el norte del estado de Puebla. Boletín de la Sociedad Botánica de México 4: 10-12. 
no tiene más que una especie en México, mientras en los Estados Unidos, varias. Crece en lugares asoleados, sobre todo en rocas calizas.

Cerca de Pahuatlán, en bosques de encinos, encontramos Chaptalia nutans, Vaccinium geminiflora, Lycopodium complanatum, Phyllanthus, Ulmus, Agdetis, Triodon y gran cantidad de Pachyrrhyzus erosus (Jicama).

Entre Pahuatlán y Tenango de Doria hay todavía algunas selvas vírgenes que son un paraíso para el botánico. Aquí hicimos los hallazgos más notables del viaje. En primer lugar mencionaré un descubrimiento notable. Es bien sabido que la planta cultivada llamada Cobaea scandens es originaria de México, pero hasta la fecha no se la ha encontrado en estado silvestre. Esta bellísima trepadora es bastante común en los jardines y cercados no solamente de México sino en otras partes del mundo. En el pedazo de selva, cerca de Tenango de Doria, los grandes árboles, como los encinos, están materialmente cubiertos de Cobaea scandens. Es casi la única trepadora, exceptuando una Compuesta de flores grandes y amarillas, que junto con la Cobaea cubre la vegetación arbórea. Indudablemente este lugar es uno de los habitats naturales de la Cobaea. Por lo demás, la Cobaea silvestre es exactamente idéntica a la cultivada. Tiene el mismo tamaño y el mismo color y no se ha variado en casi nada en el cultivo. Todos quedamos encantados con tan importante descubrimiento.

En este pedazo de selva virgen encontramos un frondoso árbol con flores grandes, blancas y olorosas, y con las hojas trifoliadas; llamado Peltostigma pteleoides de la familia de las Rutáceas. Entre los arbustos encontrados mencionaré aquí una Beloperone y el Chileranthemum, ambos de la familia de las Acantáceas. El Chileranthemum trifidum es un género monotípico mexicano que crece también en la región de Huauchinango. Es un arbusto de porte muy elegante y las flores son casi blancas y tenues.

En los alrededores de Tenango encontramos Nyssa sylvatica, Magnolia Schiedeana, Alcornea latifolia, etc. También hay gran cantidad de Melastomáceas como Tibuchina, Conostegia, Rhexia, etc. Considero como interesante hallazgo el Centropogon grandidentatus Lobeliácea que crece en los bosques más sombríos y húmedos, casi siempre cerca de los riachuelos.

En Tutotepec visitamos los famosos bosques de Hayas (Fagus mexicana) que son casi idénticos a los bosques de Zacualtipan. Aquí se llama Totolcal. Desgraciadamente las explotan mucho y estos bosques 
están mucho más mermados que los de Zacualtipán, donde las Hayas son protegidas por el Departamento Forestal. Estas Havas crecen entre árboles de Magnolia Schiedeana, Befaria, encinos, Ardisia, Citharexylum Pringlei, y muchos helechos arborescentes, etc.

Además de estos hallazgos botánicos encontramos uno entomológico que, por su curiosidad, merece ser consignado. Cerca de Pahuatlán notamos volando entre los encinos un fantástico sér que a la primera vista no pudimos identificar. Parecía este fantasma una especie de pájaro blanco con cola blanca o una mariposa extraordinaria. Al capturarlo nos dimos cuenta de que se trataba de un insecto rarísimo. En efecto nunca habíamos visto nada semejante. En lugar de describirlo voy a mostrar algunos ejemplares que logré capturar. Al llegar a México logramos la identificación de este extraordinario insecto. El entomólogo señor C. Bolívar nos explicó que el insecto se llama LYXTRA CERIFERA. Pertenece a la familia de los Fulgoridae, tribu Homoptera. Hace sesenta años un entomólogo mexicano lo encontró en las calles de México. Se supone que desde entonces no se ha encontrado. Yo nunca lo había visto, tampoco lo habían encontrado los otros miembros de la excursión. En. México no hay más que una especie. Según. el señor Bolívar en China existen géneros parecidos al de México y allí se utiliza el insecto para la extracción de la cera.

Como cosa curiosa mencionaré que después de mi regreso a esta capital, en una de mis excursiones dominicales encontré dicho insecto en la cañada de Contreras en un encino. No encontré más que un solo ejemplar, mientras en Pahuatlán encontramos gran cantidad. Había allí encinos donde encontramos hasta veinte individuos chupando la savia de los encinos. Hace como ocho días también lo encontré en una roca cerca de Tepoztlán, Mor. El señor Bolívar lo encontró en Necaxa y en las calles de México.

Ahora bien, es un cnigma el hecho de que dicho insecto haya sido encontrado en tantos lugares y en tanta abundancia precisamente este año, mientras en años anteriores nadie lo había notado. Tal vez aparece en ciclos de varios años. Seguramente se necesitan más datos y más investigaciones sobre el particular para poder contestar estas preguntas. 